\title{
Dinâmica da regeneração natural após manejo e incêndio em área da Floresta Nacional do Tapajós
}

Em áreas de manejo é imprescindível o acompanhamento da estrutura e dinâmica da regeneração natural, tendo por base que esta é de suma importância para o processo de resiliência da floresta e para a reposição do estoque de madeira para futuros ciclos de corte. O monitoramento da vegetação também propicia informações relevantes para o planejamento das atividades de manejo que visam minimizar os impactos a vegetação remanescente. Deste modo, o estudo objetivou avaliar a composição e diversidade florística da regeneração natural em área de manejo de 100 hectares (ha) na Floresta Nacional do Tapajós, no município de Belterra (PA). O trabalho foi desenvolvido em uma Unidade de Produção Anual (UPA 07), onde houve a colheita de madeira no ano de 2012 . No final de 2015, ocorreu um incêndio florestal na área, e algumas parcelas foram atingidas pelo fogo. A UPA abrange uma área de 100 hectares (ha). Nesta, foram instaladas, aleatoriamente, 10 parcelas permanentes (PP) de 0,25 ha, cada uma com dimensões de $(50 \mathrm{~m} \times 50 \mathrm{~m})$, com um total de $2,5 \mathrm{ha}$ amostrados. Na composição florística, detectou-se uma variação entre as espécies mais abundantes da primeira para a segunda e a terceira medição 0 índice de diversidade para a área de estudo foi constante em dois períodos: antes da colheita e um ano após a colheita, reduzindo no terceiro período de acompanhamento quatro anos após a colheita. As taxas de mortalidade, ingresso e sobrevivência, presentes na tabela 2, mostram que a classe de vara teve a maior taxa de mortalidade, mas também a maior taxe ingresso, contudo as taxas de sobrevivência foram inferiores as da classe de arvoreta, de acordo com cada período de monitoramento. 0 manejo florestal realizado na área contribuir para o aumento na composição e diversidade florística da área estudada. Contudo o fogo alterou negativamente o número de espécies no terceiro período de monitoramento.

\section{Natural regeneration dynamics after management and fire in Tapajós National Forest area}

\begin{abstract}
In management areas, it is essential to monitor the structure and dynamics of natural regeneration, based on the fact that it is of paramount importance to the forest resilience process and to replenishing the wood stock for future cutting cycles. Vegetation monitoring also provides relevant information for planning management activities aimed at minimizing impacts on remaining vegetation. Thus, the study aimed to evaluate the composition and floristic diversity of natural regeneration in a management area of 100 hectares (ha) in the Tapajós National Forest, in the municipality of Belterra (PA). The work was carried out at an Annual Production Unit (UPA 07), where the wood was harvested in 2012. At the end of 2015, a forest fire occurred in the area, and some plots were hit by fire. The UPA covers an area of 100 hectares (ha). It was randomly installed 10 permanent plots (PP) of 0.25 ha, each with dimensions of (50m x 50m), with a total of 2.5 ha sampled. In the floristic composition, a variation was detected between the most abundant species from the first to the second and the third measurement. The diversity index for the study area was constant in two periods: before harvest and one year after harvest, reducing in the third follow-up period four years after harvest. The mortality, ingress, and survival rates shown in Table 2 show that the stick class had the highest mortality rate but also the highest ingress rate, but survival rates were lower than the tree class, according to each monitoring period. Forest management in the area contributes to the increase in floristic composition and diversity of the studied area. However, fire negatively altered the number of species in the third monitoring period.
\end{abstract}

Keywords: Sustainable management; Monitoring; Permanent parcels; Floristic diversity.

Topic: Ciências Florestais

Reviewed anonymously in the process of blind peer.
Received: 03/08/2018

Approved: $15 / 08 / 2018$
Maria Soliane Sousa Costa (iD)

Universidade Federal do Oeste do Pará, Brasil http://lattes.cnpq.br/3451211902811033 http://orcid.org/0000-0003-1722-5604

solianesc.m@gmail.com

\section{Lia de Oliveira Melo}

Universidade Federal do Oeste do Pará, Brasil

http://lattes.cnpq.br/7141186898784095

http://orcid.org/0000-0002-5354-7742

Icolivei@gmail.com

\section{Referencing this:}

COSTA, M. S. S.; MELO, L. O.. Dinâmica da regeneração natural após manejo e incêndio em área da Floresta Nacional do Tapajós. Revista Ibero-Americana de Ciências Ambientais, v.9, n.6, p.37-44, 2018. DOI: http://doi.org/10.6008/CBPC2179-6858.2018.006.0004 


\section{INTRODUÇÃO}

Todo processo de dinâmica florestal inicia-se com a germinação das sementes presentes no solo, dando origem as novas plântulas que após alguns anos vão compor o estrato adulto da vegetação. Esse processo de desenvolvimento das classes iniciais de uma floresta é importante para a manutenção das florestas. Desse modo a regeneração natural pode ser caracterizada como responsável pela reposição da fitomassa florestal.

Para Fiorentin et al. (2015), a regeneração natural é um fenômeno extremamente importante, altamente complexo e dinâmico, referindo-se, de modo geral, às fases iniciais do ciclo de desenvolvimento das plantas. Nesse estágio de desenvolvimento, as plantas são mais suscetíveis as perturbações, sejam de origem natural ou antrópica, e assim, sofrem as maiores flutuações populacionais.

Dentre as perturbações de origem natural, a ocorrência de incêndio é um dos mais danosos a regeneração natural, que dependendo da proporção do fogo, pode ser totalmente dizimar todo a população da área afetada pelo incêndio. Contudo, o fogo pode favorecer a geminação de espécies presentes no banco de sementes da floresta, que tem sua dormência quebrada com a presença de fogo. Por outro lado, outras espécies podem não germinar quando atingidas por altas temperaturas.

Em áreas de manejo, é imprescindível o acompanhamento da estrutura e dinâmica da regeneração natural, tendo por base que esta é de suma importância para o processo de resiliência da floresta e para a reposição do estoque de madeira para futuros ciclos de corte. Segundo Souza et al. (2002), os conhecimentos do estoque potencial e dos processos da dinâmica de crescimento são fundamentais para a utilização, em bases ecologicamente sustentáveis, dos recursos florestais, juntamente com estudos sobre sua viabilidade técnica e econômica.

O monitoramento da vegetação também propicia informações relevantes para o planejamento das atividades de manejo que visam minimizar os impactos a vegetação remanescente. Deste modo, o estudo objetivou avaliar a composição e diversidade florística da regeneração natural após manejo e após incêndio florestal em área de 100 hectares (ha) na Floresta Nacional do Tapajós, no município de Belterra (PA).

\section{DISCUSSÃO TEÓRICA}

O manejo florestal Sustentável, também chamado de exploração de impacto reduzido, permite que a floresta se recupere até a próxima colheita, uma vez que são deixadas árvores em pé e é realizado planejamento para redução dos danos à toda a vegetação, inclusive à regeneração natural, presente no subbosque da floresta (HIRAl et al., 2012).

O sub-bosque é uma forma importante de nicho ecológico para o estabelecimento das espécies que irão compor os demais estratos, mantendo a diversidade e a sobrevivência das mesmas dentro de um ecossistema (OLIVEIRA et al., 2005). Assim, conhecer a dinâmica da composição florística do sub-bosque auxilia a compreensão da comunidade (MENDES et al., 2012).

O conhecimento da composição florística e da estrutura da floresta permite o planejamento e estabelecimento de sistemas de manejo com produção sustentável, e a condução da floresta a uma estrutura 
balanceada, bem como práticas silviculturais adequadas (SOUZA et al., 2006). Essas práticas são fundamentais para a manutenção dos recursos naturais. Segundo Souza et al. (2002), os estoques dos recursos naturais renováveis não são fixos, podendo estes tanto crescer, quanto decrescer, de onde se conclui que sua dinâmica é bastante particular. Esse recurso aumentará se for permitida a regeneração do estoque e decrescerá se esta não for permitida.

A regeneração natural pode ocorrer a partir de estímulos antrópicos ou naturais. Para Venturoli et al. (2011), independentemente do distúrbio que dá início à sucessão, morte de árvores mais velhas ou a queda de árvores por vento ou outras causas quaisquer, a abertura de clareiras e seus processos associados ocasionam fortes flutuações no ambiente luminoso do sub-bosque. Essas aberturas favorecem a entrada de luminosidade que aceleram o processo de sucessão.

Embora a floresta esteja em dinâmica contínua, há um equilíbrio em florestas naturais, onde as árvores mortas são continuamente substituídas por novos indivíduos. Em geral, as áreas de clareiras apresentam recrutamento superior à mortalidade; a fase de construção tende para o equilíbrio por um curto período, em seguida a mortalidade ultrapassa o ingresso (CARVALHO, 1997). A duração de cada fase depende da magnitude do distúrbio, estando a dinâmica das mudanças diretamente relacionada ao grau de abertura no dossel florestal (OLIVEIRA et al., 2005).

Estudos apontam que distúrbios causados pela presença de fogo em florestas tropicais dificultam o desenvolvimento de novas plântulas, pois o fogo favorece a presença de gramíneas, estas em competição com as espécies arbóreas impedem seu desenvolvimento, e consequente estabilização no sub-bosque das florestas (MELO et al., 2010).

\section{METODOLOGIA}

\section{Descrição da área de estudo}

A área de estudo está localizada no município de Belterra, no estado do Pará. O estudo foi realizado na área de manejo da unidade de conservação Floresta Nacional do Tapajós, a altura do km 83 da Rodovia Santarém-Cuiabá (BR-163), sob as coordenadas S02 $53^{\prime} 08,0^{\prime \prime}$ e W054 $55^{\prime} 16,7^{\prime \prime}$. A altitude da área está em torno de $175 \mathrm{~m}$ acima do nível do mar, onde o relevo é considerado plano a levemente ondulado. No solo dessa região, há uma predominância de Latossolo Amarelo Distrófico, caracterizado por diferentes texturas, geralmente profundo, ácido, friável e revestido por florestas densas (ESPÍRITO-SANTO, 2005).

Segundo a classificação de Köppen (1928), o clima é do tipo Ami. A temperatura média anual gira em torno de $25^{\circ} \mathrm{C}$, com médias mínimas de $18,4^{\circ} \mathrm{C}$ e máximas de $32,6^{\circ} \mathrm{C}$. A umidade relativa é de aproximadamente $86 \%$ (com variações entre 76-93\%). A média anual de chuvas está em torno de $2.110 \mathrm{~mm}$, com um período chuvoso de março a maio e período seco ou pouco chuvoso de agosto a novembro (CARVALHO, 2001). A vegetação da área é bastante diversificada com presença de diversas tipologias florestais, contudo a predominância é de floresta ombrófila densa de terra firme (ICMBIO, 2004).

A área do estudo vem sendo submetida a manejo florestal desde o ano de 2006 com exploração de impacto reduzido pela Cooperativa Mista da FLONA do Tapajós (COMFLONA). A principal área de manejo 
tem aproximadamente 32.000 ha. O acompanhamento da dinâmica e estrutura da floresta vem sendo de relevante importância para a tomada de decisão sobre a implementação do manejo florestal conduzido. 0 monitoramento da área é realizado pelo grupo de pesquisa de Monitoramento da Estrutura e Dinâmica Florestal (MEDFLOR), integrado ao Laboratório de Manejo de Ecossistemas Florestais (LAMEF) do Instituto de Biodiversidade e Florestas (IBEF) da Universidade Federal do Oeste do Pará-UFOPA, através de parceria firmada com a cooperativa.

\section{Coleta e análise de dados}

O trabalho foi desenvolvido em uma Unidade de Produção Anual (UPA 07), onde houve a colheita de madeira no ano de 2012, e no final de 2015 ocorreu um incêndio florestal na área. A UPA estudada abrange uma área de 100 hectares (ha). Nesta, foram instaladas aleatoriamente 10 parcelas permanentes (PP) de 0,25 ha cada com dimensões de $(50 \mathrm{~m} \times 50 \mathrm{~m})$, com um total de 2,5ha amostrados.

A instalação das parcelas permanentes foi baseada na metodologia de Silva et al. (2005), onde cada parcela $(50 \mathrm{~m} \times 50 \mathrm{~m})$ é dividida em unidades menores (subparcelas) de $10 \mathrm{~m} \times 10 \mathrm{~m}$, onde são medidas as arvoretas, e dentro de cada subparcelas é selecionada uma faixa de $2,5 \mathrm{~m} \times 10 \mathrm{~m}$ para medição das varas e dentro desta uma faixa menor de 2,5m x $5 \mathrm{~m}$ para contagem das mudas; essas subdivisões facilitam a localização e o controle de cada indivíduo monitorado, de acordo com suas dimensões ou classe de tamanho. Para esse estudo, foram considerados as seguintes classes de diâmetro a $1,30 \mathrm{~m}$ do solo: arvoretas $(5 \mathrm{~cm} \leq$ DAP $<10 \mathrm{~cm}$ ), para varas $2,5 \mathrm{~cm} \leq$ DAP $<5 \mathrm{~cm}$ e mudas ALTURA $>30 \mathrm{~cm}$ e DAP $\leq 2,57 \mathrm{~cm}$. As medições foram realizadas em três ocasiões, antes da colheita, um ano após a colheita e três anos após a segunda medição.

Foram realizadas as análises para a composição florística, diversidade florística pelo índice de Shannon - Wiener, e taxas de crescimento dos indivíduos, taxas de mortalidade, de recrutamento, e sobrevivência, para os cálculos foram considerados os três períodos de monitoramento. Sendo retratado neste estudo como antes da colheita, um ano após a colheita e quatro anos após a colheita. O software Manejo de Florestas Tropicais foi utilizado para tabulação dos dados e geração de resultados, para os parâmetros estruturais e para dinâmica. A análise estatística foi realizada para o índice de Shannon - Wiener, teste t pareado, por meio do programa Action versão 2.8.

\section{RESULTADOS}

A área apresentou, na primeira medição, um total de 947 indivíduos representando 379ind.ha ${ }^{-1}$, entre arvoretas, varas e mudas, na segunda esse número foi bem superior totalizando 1127 indivíduos (451ind.ha ${ }^{-1}$ ). Na terceira medição foram registados 882 indivíduos (353ind.ha-1 ${ }^{-1}$. A segunda medição que apresentou o maior número de indivíduos também apresentou o maior número de espécies (figura 1).

Na composição florística detectou-se uma variação entre as espécies mais abundantes da primeira, para a segunda e a terceira medição, conforme se pode visualizar na figura 2 . A espécie mais presente dentre todas as ocasiões foi a Ocotea sp. e a Ormosia paraensis. O índice de diversidade para a área de estudo foi constante em dois períodos, entes da colheita e um ano após a colheita, reduzindo no terceiro período de 
acompanhamento quatro anos após a colheita (tabela 1). As taxas de mortalidade, ingresso e sobrevivência, presentes na tabela 2, mostram que a classe de vara teve a maior taxa de mortalidade, mas também a maior taxe ingresso, contudo as taxas de sobrevivência foram inferiores as da classe de arvoreta, de acordo com cada período de monitoramento.

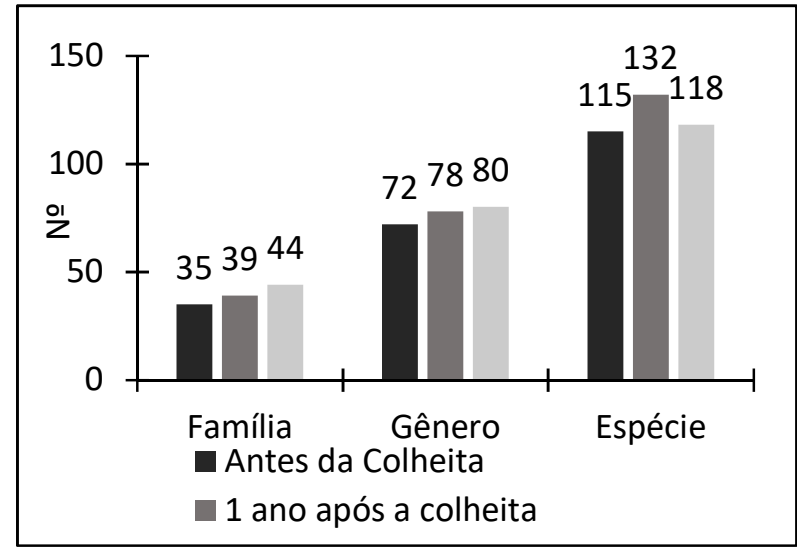

Figura 1: Número de famílias, gêneros e espécies na UPA 7 na Floresta Nacional do Tapajós.

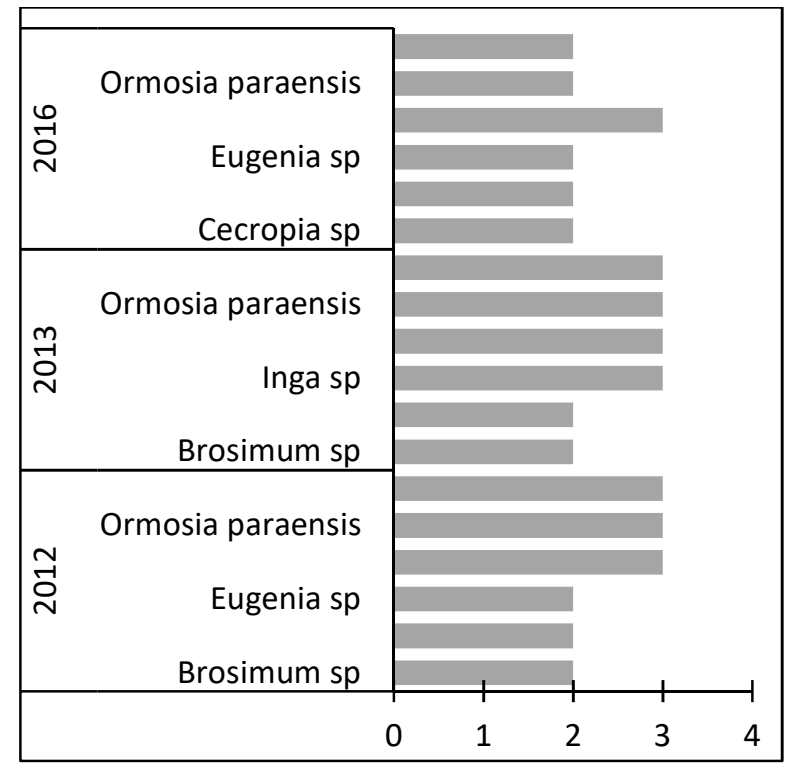

Figura 2: Espécies mais abundantes nos três períodos de monitoramento na área de manejo da UPA 7 na Floresta Nacional do Tapajós.

Tabela 1: Índice de diversidade de Shannon-Weaver para a UPA 7 na Floresta Nacional do Tapajós, nos anos de 2012 (antes da colheita), 2013 (1 ano após a colheita) e 2016 (três anos após a colheita).

\begin{tabular}{|l|l|l|}
\hline Medições & Shannon-Weaver & Equabilidade de Pielou \\
\hline Antes da colheita & 3,26 & 0,79 \\
\hline 1 ano após a colheita & 3,36 & 0,80 \\
\hline 4 anos após a colheita & 3,21 & 0,81 \\
\hline
\end{tabular}

Tabela 2: taxas de mortalidade, ingresso e sobrevivência para arvoretas e varas em área manejada na Floresta Nacional do Tapajós.

\begin{tabular}{|l|l|l|l|l|l|l|l|}
\hline Classe & Período & M/ha & M\% & I/ha & I\% & S/há & S\% \\
\hline \multirow{2}{*}{ Arvoreta } & $2012-2013$ & 58,2 & 10,4 & 52,7 & 9,4 & 498,2 & 89,0 \\
\cline { 2 - 8 } & $2013-2016$ & 73,7 & 41,3 & 4,7 & 2,6 & 301,8 & 53,9 \\
\hline \multirow{2}{*}{ Vara } & $2012-2013$ & 172,7 & 13,1 & 81,8 & 6,2 & 1163,6 & 88,3 \\
\cline { 2 - 8 } & $2013-2016$ & 241,8 & 59,9 & 17,7 & 4,4 & 490,9 & 37,2 \\
\hline \multirow{2}{*}{ Média (Arvoreta+ Vara) } & $2012-2013$ & 115,5 & 11,7 & 67,3 & 7,8 & 830,9 & 88,6 \\
\cline { 2 - 8 } & $2013-2016$ & 157,7 & 50,6 & 11,2 & 3,5 & 396,4 & 45,6 \\
\hline
\end{tabular}

Legenda: ${ }^{*} \mathrm{M} / \mathrm{ha}=$ Mortalidade por hectare; $\mathrm{M} \%=$ mortalidade em porcentagem; $\mathrm{I} / \mathrm{ha}=$ ingresso por hectare; $\mathrm{l} \%=$ ingresso em porcentagem; $\mathrm{S} / \mathrm{ha}=$ sobrevivência por hectare; $\mathrm{S} \%$ = sobrevivência em porcentagem.

\section{DISCUSSÃO}

A variação no número de indivíduos provavelmente se deu em função das aberturas no dossel que favorecem a entrada de luminosidade, essencial para o desenvolvimento das plântulas. Na terceira medição, ocorreu um número inferior até mesmo a primeira medição, essa redução pode ter ocorrido em função da presença de fogo, que queimou grande parte da vegetação da área. 


\section{Composição florística}

Os indivíduos mensurados estão distribuídos em diversas espécies dentro da UPA. O número de espécies reflete a ocorrência do incêndio florestal, assim como, para o número de indivíduos que decresceu no terceiro período em relação ao segundo, o mesmo ocorreu para o número de espécies. Para números de família e gênero o aumento foi gradual da primeira para a terceira medição indicando um aumento na riqueza botânica da área em estudo, notável na figura 1.

Lima Filho et al. (2002) avaliou três hectares de floresta ombrófila densa de terra firme na região do rio Urucu no estado do Amazonas, e a distribuição da composição florística para a regeneração natura obteve maiores valores para número de famílias e gêneros contudo o número de espécies foi inferior ao encontrado na Flona do Tapajós no presente estudo.

Hirai et al. (2012) avaliou o efeito da exploração florestal de impacto reduzido sobre a regeneração natural em uma floresta densa de terra firme no município de Paragominas (PA). Eles encontraram valores inferiores as deste estudo, para área remanescente de exploração e para área não explorada (79 e 59 espécies, respectivamente), mesmo sendo uma área de floresta similar à da Floresta Nacional do Tapajós e com o mesmo nível de inclusão que o deste estudo.

Os resultados para a composição florística indicam que a colheita florestal a partir das técnicas de baixo impacto realizado na UPA estudada, pode ter contribuiu para o crescimento em número de espécies, gêneros e famílias. A variação nas espécies mais abundantes nos diversos períodos de monitoramento, como mostra a figura 2, indica o quanto a floresta é dinâmica e suscetível aos distúrbios ambientais, sejam de causar natural ou antrópica, pois apesar de a Cecropia ser uma espécie oportunista, ela não está no topo da lista nem na segunda nem na terceira medição, que tem por característica o surgimento em áreas de clareira, ela aparece no segundo e terceiro período dentre as mais abundantes devido as aberturas no dossel após a colheita de madeira e após a presença do fogo.

No estudo de Hirai et al. (2012), mesmo na área explorada onde houve a abertura de clareiras a Cecropia $s p$, não foi descrita entre as de maior densidade no estudo. As espécies mais abundantes foram Rinorea guianensis, Sagotia rancemosa, Poecilanthe efusa, Inga alba e Rinorea rancemosa. A família da Fabaceae que foi a mais representativa também se destacou na regeneração natural em número de indivíduos e famílias no estudo realizado por Higuchi et al. (2006) da composição florística da regeneração natural de espécies arbóreas ao longo de oito anos em um fragmento de floresta estacional semidecidual, em Viçosa (MG).

\section{Diversidade florística}

Para a diversidade florística, o índice de Shannon-Weaver indicou valores superiores a 3,0 para todos os períodos de monitoramento, sendo maior na segunda medição. A equabilidade de Pielou variou entre os períodos, seu maior na terceira ocasião superou as demais mesmo tendo o menor índice de diversidade (tabela 1). Hirai et al. (2012) não detectou valores de diversidade de Shannon superiores a 1,5, o que aponta 
para uma maior diversidade na área manejada na Floresta Nacional do Tapajós em relação a floresta estudada em Paragominas.

Souza et al. (2006) alisou a estrutural em floresta ombrófila densa de terra firme não explorada na Amazônia Oriental, e para o nível de inclusão de $15 \mathrm{~cm} \leq$ dap $<15 \mathrm{~cm}$, verificou valores de diversidade de 4,18 pelo índice de Shannon, sendo que a área de amostragem foi bem superior à deste estudo, o que provavelmente influenciou em maior índice. $O$ teste estatístico apontou diferença altamente significativa ao nível de $99 \%$ de probabilidade para os dois intervalos analisados com P-valor $=0,0018$ para a comparação entre 2012 e 2013, e P-valor = 0,0150 entre 2013 e 2016.

\section{Mortalidade, ingresso e sobrevivência}

As taxas de mortalidade apontam a classe de varas como mais suscetíveis a distúrbios ambientais, com valores superiores aos de arvoreta. Contudo, as duas classes apresentaram maior mortalidade entre 2013 a 2016, sendo que foi no final deste intervalo que ocorreu o incêndio florestal que atingiu a área. Mesmo a classe de varas sendo mais sensível as perturbações, essa também se apresentou com maior resiliência, tendo as maiores taxas de ingresso nos dois períodos após a colheita e após o fogo, conforme se demonstrou na tabela 2.

Hirai et al. (2012) também detectou que, após a extração de madeira, a taxa de ingresso aumentou na área explorada, corroborando para a teoria de que as aberturas no dossel da floresta contribuem para o desenvolvimento das plantas do sub-bosque. No estudo da dinâmica da regeneração natural em três estágios sucessionais, realizado por Schorn et al. (2006) também apontou uma maior taxa de ingresso e menor taxa de mortalidade na regeneração natural em uma floresta ombrófila densa e Santa Catarina. A taxa de sobrevivência diminuiu bastante no período de 2013 a 2016, ou seja, o fogo que ocorreu no fim de 2015 causou maior dando a vegetação que a colheita que ocorreu em 2012. A taxa de mortalidade foi superior as taxas de ingresso para as duas classes em todos os períodos.

\section{CONCLUSÕES}

A dinâmica e a estrutura da regeneração natural foram alteradas pelo dois eventos ocorridos: o manejo e o fogo. O manejo florestal, com base em técnicas de baixo impacto, realizado na área contribuiu para o aumento na composição e diversidade florística da área estudada. Contudo, o fogo alterou negativamente o número de espécies no terceiro período de monitoramento.

Quanto às taxas de mortalidade, ingresso e sobrevivência, a regeneração natural apresentou-se altamente suscetível aos distúrbios ocorridos, tanto os de origem antrópicas quanto aos de origem natural, tendo maior taxa de mortalidade do que de ingresso em todos os períodos e para todas as classes avaliadas. O estudo aponta ainda a necessidade de continuidade do monitoramento da área, para avaliar ao longo do tempo os efeitos causados pelo manejo e fogo, e o tempo que a regeneração natural leva para se restabelecer lapós ter sido atingidas por perturbações tanto de origem antrópica quanto Natural em um curto intervalo de tempo. 


\section{REFERÊNCIAS}

CARVALHO, J. O. P.. Dinâmica de florestas naturais e sua implicação para o manejo florestal. In: SIMPÓSIO SILVICULTURA NA AMAZÔNIA ORIENTAL. Anais. Belém: Embrapa, 1997.

CARVALHO, J. O. P.. Estrutura de matas altas sem babaçu na Floresta Nacional do Tapajós. In: SILVA, J. N. M.; CARVALHO, J. O. P.; YARED, J. A. G.. A silvicultura na Amazônia Oriental: contribuições do projeto Embrapa/DFID. Belém: Embrapa Amazônia Oriental, 2001. p.277-290.

ESPÍRITO-SANTO, F. D. B.; SHIMABUKURO, Y. E.; ARAGÃO, L. E. O. C.; MACHADO, E. L. M.. Análise da composição florística e fitossociológica da floresta nacional do Tapajós com o apoio geográfico de imagens de satélites. Acta Amazônica, São Paulo, v.35, n.2, p.155-173, 2005.

FIORENTIN, L. D.; TÉO S. J.; SCHNEIDER, C. R.; COSTA, R. H.; BATISTA, S.. Análise Florística e Padrão Espacial da Regeneração Natural em Área de Floresta Ombrófila Mista na Região de Caçador, SC. Floresta e Ambiente, v.22, n.1, p.60-70, 2015.

HIGUCHI, P.; REIS, M. G. F.; REIS, G. G.; PINHEIRO, A. L.; SILVA, C. T.; OLIVEIRA, C. H. R.. Composição florística da regeneração natural de espécies arbóreas ao longo de oito anos em um fragmento de floresta estacional semidecidual, em Viçosa, MG. Revista Árvore, Viçosa, v.30, n.6, p.893-904, 2006.

HIRAI, E. H.; CARVALHO, C. J. R.; SILVA, J. N. M.; CARVALHO, J. O. P.; QUEIROZ, W. T.. Efeito da exploração florestal de impacto reduzido sobre a regeneração natural em uma floresta densa de terra firme no município de Paragominas na Amazônia brasileira. Scientia Forestalis, Piracicaba, v.40, n.95, p.306-315, 2012.

ICMBIO. Instituto Chico Mendes de Conservação da Biodiversidade. Floresta Nacional do Tapajós: Plano de manejo. Brasília: ICMBIO, 2004.

KÖPPEN, W.; GEIGER, R.. Klimate der Erde. Gotha: Verlag Justus Perthes, 1928.

LIMA FILHO, D. A.; REVILLA, J.; COÊLHO, L. S.; RAMOS, J. F.; SANTOS, J. L.; OLIVEIRA, J. G.. Regeneração natural de três hectares de floresta ombrófila densa de terra firme na região do Rio Urucu-AM, Brasil. Acta Amazônica, v.32 n.4, p.555-569, 2002.

MELO, A. C. G.; DURIGAN, G.. Impacto do fogo e dinâmica da comunidade vegetal em borda de Floresta Estacional
Semidecidual (Gália, SP, Brasil). Revista Brasileira de Botânica, v.33, n.1, p.37-50, 2010.

MENDES, F. S.; JARDIM, F. C. S.; CARVALHO, J. O. P.; LIMA, T. T. S.; SOUZA, D. V. Dinâmica da composição florística do subbosque em floresta tropical manejada, no município de Moju, estado do Pará, Brasil. Revista Ciências Agrárias, v.55, n.2, p.117-123, 2012.

OLIVEIRA, A. N.; AMARAL, I. L.. Aspectos florísticos, fitossociológicos e ecológicos de um sub-bosque de terra firme na Amazônia Central, Amazonas, Brasil. Acta Amazônica, São Paulo, v.35, n.1, p.1-16, 2005.

OLIVEIRA, L. C.; COUTO, H. T. Z.; SILVA, J. N. M.; CARVALHO, J. O. P. Efeito da exploração de madeira e tratamentos silviculturais na composição florística e diversidade de espécies em uma área de 136ha na Floresta Nacional do Tapajós, Belterra, Pará. Scientia Forestalis, v.69, p.62-76, 2005.

SCHORN, I. A.; GALVÃO, F.. Dinâmica da regeneração natural em três estágios sucessionais de uma floresta ombrófila densa em Blumenau, SC. Revista Floresta, Curitiba, v.36, n.1, 2006.

SILVA, J. N. M.; CARVALHO, J. O. P.; BARROS, P. L. C.; LOPES J. C. A.; SILVA, U. S. C.; OLIVEIRA, L. C.; RUSCHEL, A. R.; TAVARES, M. J. M.. Amasoft/MFT: Ferramenta para Monitoramento de Florestas Tropicais. Belém: Embrapa Amazônia Oriental, 2008.

SILVA, J. N. M.; LOPES, J. C. A.; OLIVEIRA, L. C.; SILVA, S. M A.; CARVALHO, J. O. P.; COSTA, D. H. M.; MELO, M, S.; TAVARES, M. J. M.. Diretrizes para instalação e medição de parcelas permanentes em florestas naturais da Amazônia Brasileira. Belém: Embrapa Amazônia Oriental, 2005.

SOUZA, A. L.; SCHETTINO, S.; JESUS, R. M.; VALE, A. B.. Dinâmica da composição florística de uma floresta ombrófila densa secundária, após corte de cipós, reserva natural da companhia Vale do Rio Doce S. A., estado do Espírito Santo, Brasil. Revista Árvore, Viçosa, v.26, n.5, p.549-558, 2002.

SOUZA, D. R.; SOUZA, A. L.; LEITE, H. G.; YARED, J. A. G.. Análise estrutural em floresta ombrófila densa de terra firme não explorada, Amazônia Oriental. Revista Árvore, Viçosa, v.30, n.1, p.75-87, 2006

VENTUROLI, F.; FELFILI, J. M.; FAGG, C. W.. Avaliação temporal da regeneração natural em uma floresta estacional semidecídua secundária, em Pirenópolis, Goiás. Revista Árvore, Viçosa, v.35, n.3, p.473-483, 2011.

A CBPC - Companhia Brasileira de Produção Científica (CNPJ: 11.221.422/0001-03) detém os direitos materiais desta publicação. Os direitos referem-se à publicação do trabalho em qualquer parte do mundo, incluindo os direitos às renovações, expansões e disseminações da contribuição, bem como outros direitos subsidiários. Todos os trabalhos publicados eletronicamente poderão posteriormente ser publicados em coletâneas impressas sob coordenação da Sustenere Publishing, da Companhia Brasileira de Produção Científica e seus parceiros autorizados. Os (as) autores (as) preservam os direitos autorais, mas não têm permissão para a publicação da contribuição em outro meio, impresso ou digital, em português ou em tradução. 